Special Edition "Vectors and VBDs"

Short communication

\title{
A field evaluation of an isothermal DNA amplification assay for the detection of Theileria annulata infection in cattle
}

Jacinto Gomes a,1, ${ }^{*}$ Marcos Santos ${ }^{b, 1}$, Ana Amaro a, Isabel Pereira da Fonseca ${ }^{b}$, Gabriela Santos-Gomes ${ }^{\mathrm{c}}$, João Inácio ${ }^{\mathrm{c}, \mathrm{d}}$

a Unidade Estratégica de Investigação e Serviços em Produção e Saúde Animal, Instituto Nacional de Investigação Agrária e Veterinária, I.P., Lisbon, Portugal

b Centro de Investigação Interdisciplinar em Sanidade Animal, Faculdade de Medicina Veterinária, Universidade de Lisboa, Lisbon, Portugal

c Global Health and Tropical Medicine Centre (GHTM), Instituto de Higiene e Medicina Tropical, Universidade Nova de Lisboa, Lisbon, Portugal

d School of Pharmacy and Biomolecular Sciences, University of Brighton, Brighton, United Kingdom

1 These authors contributed equally to this work

${ }^{\star}$ Corresponding author.

Abstract

A loop-mediated isothermal amplification (LAMP) assay was evaluated for the detection of Theileria annulata infection in cattle. The results were compared with a real-time PCR used for the quantification of $T$. annulata parasitaemia. One hundred bovine blood samples from 16 cattle farms were tested with LAMP and real-time PCR, with $T$. annulata DNA being detected in $66 \%$ and $67 \%$ of the samples, respectively. The results showed that the LAMP assay detects a parasitaemia as low as $0.00025 \%$, indicating a high analytical sensitivity of LAMP for clinical diagnosis of bovine theileriosis.

Keywords: molecular diagnostics; LAMP; real-time PCR; Tams1; Theileria annulata; bovine theileriosis 


\section{Introduction}

Tropical or Mediterranean Theileriosis is a tick-borne haemoprotozoan disease caused by the apicomplexan parasite Theileria annulata, responsible for important health problems in cattle (Bos taurus and Bos indicus) and in the Asian buffalo (Bubalus bubalis). Clinical disease is usually associated with tick vector infestation and the clinical diagnosis is frequently supported by microscopic examination of stained peripheral blood smears for the detection of piroplasm-infected erythrocytes or macroschizont-infected leukocytes in Giemsa-stained lymph node biopsies [1]. These methodologies are useful to detect acute cases, but have low sensitivity for the assessment of carrier animals, in which small numbers of erythrocytes remain infected, and do not allow the morphological discrimination of $T$. annulata from other species of piroplasms in mixed infections [2]. Alternative molecular diagnostic-based assays have been developed for the sensitive and specific detection of $T$. annulata infection in cattle, including a Reverse Line Blot (RLB) hybridization assay based on the amplification of the hyper-variable V4 region of the 18S rRNA gene of these parasites [3,4,5,6]. Though considered to be one of the most sensitive tests for detecting $T$. annulata by identifying very low levels of the parasite in carrier animals, the RLB technique is costly and requires a well equipped laboratory and a skilled technician [7].

Loop-mediated isothermal amplification (LAMP) is a technique for the amplification of DNA under isothermal conditions with high sensitivity. It is based on a nucleic acid amplification that relies on autocycling strand-displacement DNA synthesis, performed usually with Bst (Bacillus stearothermophilus) DNA polymerase. This enzyme can synthesize a new strand of DNA, while simultaneously displacing the complementary strand, thereby enabling DNA amplification under isothermal conditions [8]. LAMP has been used successfully for the diagnosis of parasitic infections, such as malaria, trypanosomiasis and toxoplasmosis, being reported as a highly sensitive and specific method $[9,10,11]$. LAMP assays were also formerly described for the detection of Theileria parasites $[12,13,14,15,16]$, including $T$. annulata $[17,18]$.

We formerly described the experimental details of a LAMP-based molecular assay allowing the specific detection of $T$. annulata in bovine blood samples by targeting the parasite major merozoite surface antigen (Tams1) gene [19]. A field study is described here, where the Tams1-targeted assay was validated using a large set of blood samples collected from cattle from a theileriosis endemic area at southern Portugal. A real-time PCR test was used to estimate parasitaemia in naturally infected cattle. 


\section{Materials and methods}

Blood samples were collected from individual cattle (of different ages) in EDTA tubes between January and June 2012 from sixteen farms in southern Portugal. One hundred samples were taken from animals older than six months, with no apparent clinical signs of theileriosis. A total of $800 \mu \mathrm{l}$ of whole blood was used for DNA extraction. Red cells were lysed using distilled water and centrifuged at $4,500 \times \mathrm{g}$ ( 2 cycles of $5 \mathrm{~min}$ ). The supernatant was discarded and the remaining pellet was reconstituted with $200 \mu$ of water, and DNA extracted using the High Pure PCR Template Preparation Kit (Roche, Switzerland) according to the manufacturer's instructions. A DNA sample extracted from a $T$. annulata-infected macrophage culture obtained from a calf with clinical diagnosis of theileriosis (confirmed by microscopical examination of Giemsa-stained smears and RLB assay) and a reference blood sample (sample 8182) with an estimated $T$. annulata parasitaemia of $0.03 \%$ were included as positive controls. DNA samples from the blood of an uninfected animal, DNA from each Babesia bovis, B. bigemina and Theileria buffeli and a negative control consisting of sterile distilled water (GIBCO, Invitrogen) were also used. All samples and controls were simultaneously tested with both the LAMP [19] and real-time PCR $[6,19]$ assays as described previously.

For the quantification of parasitaemia, a real-time PCR was performed using serial dilutions of an amplified Tams1 gene fragment. Briefly, a sequence of 851 bp containing the target regions of the Tams1 gene was amplified as described by Gubbels et al. [20] using $T$. annulata DNA extracted from cell culture as template. The amplification product was purified using illustra GFX ${ }^{\mathrm{TM}}$ PCR DNA and the Gel Band Purification Kit (GE Healthcare), the DNA concentration was measured with Nanodrop ${ }^{\circledR} 2000$ (Thermo Scientific) and the copy number was determined [21]. Logarithmic genomic DNA dilution series from $10^{-2}$ to $10^{-10}$ gene copies were tested in triplicate with real-time PCR and the cycle threshold $(\mathrm{Ct})$ values were used for the standard curve elaboration. Since the Tams1 gene is a single copy gene, the curve equation could be used to quantify the copy number and consecutively to estimate the number of parasites in each sample. Using the average number of bovine erythrocytes of $7.5 \times 10^{6}$ per microliter of blood, the volume used for DNA extraction and the volume for DNA elution buffer, it was possible to estimate $T$. annulata parasitaemia. A reference blood sample with a known $T$. annulata parasitaemia of $0.03 \%$ determined by microscopy was also used as a reference control. The Cohen's kappa coefficient was used to calculate the degree of agreement between LAMP and real-time PCR assays [22]. 


\section{Results}

102 A total of 100 DNA samples extracted from bloods from asymptomatic bovines were 103 screened for the detection of $T$. annulata by LAMP and real-time PCR. A characteristic ladder pattern of a positive LAMP reaction was observed for 66 samples. The real-time PCR assay was able to detect 67 positive samples. Only one positive sample by realtime PCR was not identified by LAMP. Animals infected with $T$. annulata were detected in 14 of the 16 farms sampled. The agreement analysis determined by kappa test gave a value of 0.87 , showing an almost perfect agreement between the LAMP and real-time PCR assays.

A calibration standard curve was prepared in order to estimate the parasitaemia with real-time PCR. A plot of the threshold cycle versus the log of the initial template copy number (serial dilutions of Tams1 gene fragments) showed a linear regression. The standard curve presented a high efficiency (98\%), an acceptable slope (-3.3708) and a very good correlation (r2) (0.99) (data not shown). The 66 LAMP-positive samples showed Ct values in the real-time PCR between 21.42 and 31.05, with a mean Ct of 25.61 ( $\mathrm{Cl}$ 95\%: 26.09 - 27.13) and a standard deviation of 2.11. These $\mathrm{Ct}$ values correspond to parasitaemias ranging from $0.00026 \%$ to $0.185 \%$ and a mean parasitaemia of $0.0001 \%$. The positive sample detected only by real-time PCR showed a Ct of 38.31, corresponding to an estimated parasitaemia of $0.0000018 \%$. The reference sample 8182, with a known parasitaemia of $0.03 \%$ determined by light microscopy was shown to be positive for $T$. annulata by both LAMP and real-time PCR, with a Ct value of 25 and an estimated parasitaemia of $\sim 0.025 \%$. Ct values obtained for positive and reference samples are shown in Fig. 1.

\section{Discussion}

Bovine blood samples collected in Alentejo, an endemic region of theileriosis located in southern Portugal, were used in a field study to demonstrate the suitability of LAMP as a diagnostic tool and also to detect $T$. annulata-infected carrier animals. The prevalence of $T$. annulata-infected cattle in Alentejo region was recently found to be $\sim 29 \%$ [23]. Most clinical cases of theileriosis occur in young calves and a high number of older animals are infected without showing clinical signs and are thus considered chronic carriers.

LAMP was compared with a targeted $T$. annulata real-time PCR test used in our reference laboratory. The sensitivity of this real-time PCR test was previously assessed using Reverse Line Blot as golden standard [6]. The overall sensitivity was estimated as $90 \%$, with negative and positive predictive values of $87 \%$ and $100 \%$, respectively $[6,24]$. 
In the present study, LAMP showed an almost perfect agreement with the real-time PCR results. The LAMP assay was able to detect $T$. annulata DNA in blood samples with a very low parasitaemia, with a value of $0.00026 \%$ considered as the detection limit. Infected samples not detected by LAMP might have parasitaemias under the limit of detection or a mixed piroplasm infection [24]. By targeting the $T$. annulata-specific Tams1-encoding gene, we also ensure enhanced specificity of our molecular assays for the detection of this parasite. Former studies regarding the molecular detection of $T$. annulata using LAMP, targeting both 18S rRNA and ITS genes and a hypothetical protein gene, estimated the sensitivity of their assays to be between $0.1 \mathrm{pg} / \mu \mathrm{l}$ and $10 \mathrm{pg} / \mu \mathrm{l}$ $[17,18]$. In both studies, sensitivity assays were performed using dilutions of template DNA, but none was correlated with a known or estimated parasitaemia, hampering a direct comparison with the results of the present study. Theileria annulata is estimated to have only two copies of the $18 \mathrm{~S}$ ribosomal RNA gene [25]. Consequently, great improvements on the sensitivity of molecular assays are not expected only by targeting this gene, when compared to single copy genes such as the Tams1-encoding gene. In other studies targeting Theileria infections, real-time PCR assays were able to detect similar parasitaemia values, such as $0.0009 \%$ with $T$. parva and $0.0002 \%$ with $T$. equi $[26,27]$. A LAMP assay for $T$. sergenti was able to detect a positive blood dilution corresponding to $0.000002 \%$ parasitaemia [13].

Natural infection results in parasitaemias of $\sim 0.1$ to $0.01 \%$ in carrier animals [28]. In the present study, where none of the animals showed clinical signs of disease, the infected animals could be considered healthy carriers. We analysed the $\mathrm{Ct}$ distribution and correlated parasitaemia. Excluding the outlier value $(\mathrm{Ct}=38.31)$, it is possible to see a Ct distribution between approximately 21 and 31, with a mean value of 26 (Fig. 1). These values correspond to a parasitaemia of $0.00025 \%$ to $0.18 \%$, with a mean value of $0.009 \%$ and might be evidence of a pattern in the parasitaemia of carrier animals, which are difficult to detect by microscopy of blood smears. The LAMP assay was able to detect all samples within this range of parasitaemia and, thus, we might also expect to detect animals with overt clinical signs in which parasitemias can reach much higher values of $10 \%$ to $45 \%$ [29]. This study indicated the utility of LAMP for the detection of $T$. annulata parasites in carrier animals and also its potential applicability to the clinical diagnosis of the disease. 
172 The authors thank all of the veterinarians who provided cattle blood samples, namely

173 Jaime Ribeiro, Lina Costa, Maria do Carmo Feliciano and Carlos Gonçalves.

\section{References}

[1] OIE, World Organization for Animal Health, Theileriosis, in: Manual of Diagnostic

[2] Y. M'Ghirbi, A. Hurtado, J.F. Barandika, K. Khlif, Z. Ketata, A. Bouattour, A molecular survey of Theileria and Babesia parasites in cattle, with a note on the distribution of ticks in Tunisia. Parasit. Res. 103 (2008) 435-442.

[3] C. d'Oliveira, M. van der Weide, M.A. Habela, P. Jacquiet, F. Jongejan, Detection of Theileria annulata in blood samples of carrier cattle by PCR, J. Clin. Microbiol., 33 (1995), 2665-2669.

[4] J.M. Gubbels, A.P. de Vos, M. van der Weide, J. Viseras, L.M. Schouls, E. de Vries, F. Jongejan, Simultaneous detection of bovine Theileria and Babesia species by reverse line blot hybridization, J. Clin. Microbiol., 37 (1999), 17821789.

[5] H.B. Bilgiç, T. Karagenç, B. Shiels, A. Tait, H. Eren, W. Weir, Evaluation of cytochrome $b$ as a sensitive target for PCR based detection of $T$. annulata carrier animals, Vet. Parasitol., 174 (2010), 341-347.

[6] M. Santos, R. Soares, P. Costa, A. Amaro, J. Inácio, J. Gomes, Revisiting the Tams1-encoding gene as a species-specific target for the molecular detection of Theileria annulata in bovine blood samples, Tick Tick-Borne Dis. 4 (2013), 72-77.

7] H.B. Bilgiç, T. Karagenç, M. Simuunza, B. Shiels, A. Tait, H. Eren, W. Weir, Development of a multiplex PCR assay for simultaneous detection of Theileria annulata, Babesia bovis and Anaplasma marginale in cattle, Exp. Parasitol. 133 (2013) 222-229

[8] T. Notomi, H. Okayama, H. Masubuchi, T. Yonekawa, K. Watanabe, N. Amino, T. Hase, Loop-mediated isothermal amplification of DNA, Nucleic Acids Res. 28 (2000), E63.

[9] E.T. Han, R. Watanabe R, J. Sattabongkot, B. Khuntirat, J. Sirichaisinthop, H. Iriko, L. Jin, S. Takeo, T. Tsuboi, Detection of four Plasmodium species by genusand species-specific loop-mediated isothermal amplification for clinical diagnosis, J. Clin. Microbiol. 45 (2007), 2521-8.

[10] H. Zhang, O.M. Thekisoe, G.O. Aboge, H. Kyan, J. Yamagishi, N. Inoue, Y. Nishikawa, S. Zakimi, X. Xuan, Toxoplasma gondii: sensitive and rapid detection of infection by loop-mediated isothermal amplification (LAMP) method, Exp. Parasitol. 122 (2009), 47-50.

[11] Z. K. Nijru, Rapid and sensitive detection of human African trypanosomiasis by loop-mediated isothermal amplification combined with a lateral-flow dipstick, Diagn. Microbiol. Infect. Dis., 69 (2011), 205-9.

[12] A. Alhassan, O.M. Thekisoe, N. Yokoyama, N. Inoue, M.Y. Motloang, P.A. Mbati, H. Yin, Y. Katayama, T. Anzai, C. Sugimoto, I. Igarashi. Development of loopmediated isothermal amplification (LAMP) method for diagnosis of equine piroplasmosis. Vet. Parasitol. 143 (2007), 155-160. 
[13] Wang LX1, He L, Fang R, Song QQ, Tu P, Jenkins A, Zhou YQ, Zhao JL. Loopmediated isothermal amplification (LAMP) assay for detection of Theileria sergenti infection targeting the p33 gene, Vet. Parasitol. 171 (2010) 159-62.

[14] A. Liu, G. Guan, P. Du, H. Gou, J. Zhang, Z. Liu, M. Ma, Q. Ren, J. Liu, J. Yang, Y. Li, Q. Niu, Q. Bai, H. Yin, J. Luo. Rapid identification and differentiation of Theileria sergenti and Theileria sinensis using a loop-mediated isothermal amplification (LAMP) assay. Vet. Parasitol. 191 (2013), 15-22.

[15] O.M. Thekisoe, N.E. Rambritch, R. Nakao, R.S. Bazie, P. Mbati, B. Namangala, I. Malele, R.A. Skilton, F. Jongejan, C. Sugimoto, S. Kawazu, N. Inoue. Loopmediated isothermal amplification (LAMP) assays for detection of Theileria parva infections targeting the PIM and p150 genes. Int. J. Parasitol. 40 (2010), 55-61.

[16] D.A. Salih, A.M. Ali, Z. Liu, M.A. Bakheit, K.M. Taha, A.H. El Imam, B. Kullmann, A.M. El Hussein, J.S. Ahmed, U. Seitzer. Development of a loop-mediated isothermal amplification method for detection of Theileria lestoquardi. Parasitol. Res. 110 (2012), 533-538.

[17] A. Liu, G. Guan, P. Du, Z. Liu, H. Gou, J. Liu, J. Yang, Y. Li, M. Ma, Q. Niu, Q. Ren, Q. Bai, H. Yin, J. Luo, Loop-mediated isothermal amplification (LAMP) assays for the detection of Theileria annulata infection in China targeting the 18S rRNA and ITS sequences, Exp. Parasitol. 131 (2012) 125-129.

[18] D. A. Salih, Z. Liu, M. A. Bakheit, A. M. Ali, A. M. El Hussein, H. Unger, G. Viljoen, U. Seitzer, J. S. Ahmed, Development and Evaluation of a Loop-Mediated Isothermal Amplification Method for Diagnosis of Tropical Theileriosis. Transbound. Emerg. Dis., 55 (2008) 238-243

[19] J. Gomes, J. Inácio, Direct detection of Theileria annulata in bovine blood samples using standard and isothermal DNA amplification approaches. Methods Mol Biol. 1247 (2015), 175-82.

[20] M.J. Gubbels, F. Katzer, G. Hide, F. Jongejan, B.R. Shiels, Generation of a mosaic pattern of diversity in the major merozoite-piroplasm surface antigen of Theileria annulata. Mol. Biochem. Parasitol. 110 (2000), 23-32.

[21] S. Dhanasekaran, T. M. Doherty, J. Kenneth and TB Trials Study Group, Comparison of different standards for real-time PCR-based absolute quantification, J. Immunol. Methods, 354 (2010) 34-39

[22] P.F. Watson, A. Petrie, Method agreement analysis: a review of correct methodology. Theriogenology, 73 (2010) 1167-79.

[23] J. Gomes, R. Soares, M. Santos, G. Santos-Gomes, A. Botelho, A. Amaro, J. Inácio, Detection of Theileria and Babesia infections amongst asymptomatic cattle in Portugal. Ticks Tick-Borne Dis. 4 (2013) 148-151.

[24] J. Gomes, Epidemiology, molecular diagnostics and population genetics of Theileria annulata in Portugal. PhD Thesis (2014), University of Lisbon.

[25] A. Pain, H. Renauld, M. Berriman, L. Murphy, C.A. Yeats, W. Weir, A. Kerhornou, M. Aslett, R. Bishop, C. Bouchier, M. Cochet, R.M. Coulson, A. Cronin, E.P. de Villiers, A. Fraser, N. Fosker, M. Gardner, A. Goble, S. Griffiths-Jones, D.E. Harris, F. Katzer, N. Larke, A. Lord, P. Maser, S. McKellar, P. Mooney, F. Morton, V. Nene, S. O'Neil, C. Price, M.A. Quail, E. Rabbinowitsch, N.D. Rawlings, S. Rutter, D. Saunders, K. Seeger, T. Shah, R. Squares, S. Squares, A. Tivey, A.R. Walker, J. Woodward, D.A. Dobbelaere, G. Langsley, M.A. Rajandream, D. McKeever, B. Shiels, A. Tait, B. Barrell, N. Hall. Genome of the host-cell transforming parasite Theileria annulata compared with T. parva. Science. 309 (2005) 131-3. 
[26] K. P. Sibeko, M. C. Oosthuizen, N. E. Collins, D. Geysen, N. E. Rambritch, A. A. Latif, H. T. Groeneveld, F. T. Potgieter, J. A. W. Coetzer, Development and evaluation of a real-time polymerase chain reaction test for the detection of Theileria parva infections in Cape buffalo (Syncerus caffer) and cattle, Vet. Parasitol. 155 (2008) 37-48.

[27] R. Bhoora, M. Quan, L. Franssen, C.M. Butler, J.H. Van der Kolk, A.J. Guthrie, E. Zweygarth, F. Jongejan, N.E. Collins, Development and evaluation of real-time PCR assays for the quantitative detection of Babesia caballi and Theileria equi infections in horses from South Africa, Vet. Parasitol. 168 (2010) 201-211.

[28] M. Aktas, K. Altay, N. Dumanli, A molecular survey of bovine Theileria parasites among apparently healthy cattle and with a note on the distribution of ticks in eastern Turkey, Vet. Parasitol. 138 (2006) 179-185.

[29] O.H. Omer, K.H. El-Malik, O.M. Mahmoud, E.M. Haroun, A. Hawas, D. Sweeney, M. Magzoub, Haematological profiles in pure bred cattle naturally infected with Theileria annulata in Saudi Arabia, Vet. Parasitol. 107 (2002) 161-168. 
283 Fig. 1. Representation of cycle threshold values of Theileria annulata positive samples 284 from 14 cattle farms and a reference sample (8182). A dashed line indicates the limit of 285 detection of LAMP in this study. All positive LAMP samples are below the dashed line.

286

287

288

289

290 